\title{
A REVOLUÇÃO DEMOCRÁTICA E O MOMENTO LEFORTIANO DA DEMOCRACIA BRASILEIRA ${ }^{1}$
}

Juarez Guimarães ${ }^{2}$

Resumo: Em primeiro lugar, reexaminaremos criticamente a partir de conquistas recentes da interpretação da obra de Marx, a leitura que Lefort fez obra marxiana e do marxismo ${ }^{6}$. Em seguida, e na mesma direção, faremos uma releitura da crítica e do diálogo não desenvolvido na obra de Lefort com o pensamento de Gramsci, que buscou, como ele, a reflexão com Maquiavel para renovar o marxismo. Por fim, em um momento mais praxiológico, interpretaremos o momento dramático vivido pela democracia brasileira através do conceito de revolução democrático, inscrevendo a obra de Lefort na própria cena da conjuntura brasileira.

Palavras-chaves: Claude Lefort - Marx - Gramsci - Maquiavel - democracia.

Há cinco razões convergentes para centralizar a leitura da obra de Claude Lefort em torno ao conceito de revolução democrática.

A primeira é que este conceito tem a capacidade de soldar e dar coerência de sentido às duas épocas da trajetória intelectual de Lefort, aquela que se inscreve no interior de um marxismo crítico ao processo e à natureza do estalinismo e aquela que se instaura através de Le Travail de l'cuvre Machiavel, o da redescoberta do "político" e da centralidade da democracia como instituição que forma a Modernidade.

De fato, se a primeira época referida o levará das insuficiências da crítica de Trostky e da cultura do bolchevismo ao questionamento da própria obra de Marx a partir do trágico desencontro histórico entre revolução e democracia na URSS ${ }^{3}$, após fundar um pensamento a partir de uma renovada e classicizante interpretação de Maquiavel, a obra de Marx nunca deixará de ser relida e interrogada por Lefort, que retornará ao tema do totalitarismo, sua gênese e inscrição como um possível na Modernidade.

A segunda razão para colocar no centro o conceito de revolução democrática está na fixação de sua identidade como pensador em relação às tradições que organizam a política na Modernidade. A tentação de pensá-lo como um pensador situado na fronteira entre

\footnotetext{
${ }^{1}$ Dossiê Claude Lefort: esse texto é parte do dossiê publicado a partir das comunicações realizadas no Colóquio Internacional Claude Lefort: a invenção democrática hoje, realizado na Universidade de São Paulo entre os dias 13 e 16 de outubro de 2015.

2 Professor do Departamento de Ciência Política da Universidade Federal de Minas Gerais

${ }^{3}$ LEFORT, Claude. «La contradiction de Trotsky ». In : Éléments d'une critique de la bureaucratie. Paris : Éditions Gallimard, 1974.
} 
liberalismo e socialismo, na indeterminação de um democratismo radical ou, mais simplesmente como um pensador sincrético, um "socialista liberal" ou um "liberal socialista", como queria Norberto Bobbio, vem certamente de uma cultura que identifica socialismo unicamente ao marxismo em qualquer uma das suas expressões ou subculturas ${ }^{4}$.

O conceito de revolução democrática é fundamental para a identificação de Lefort como um socialista democrático, isto é, como um crítico do liberalismo e da sociedade capitalista mas que persegue um socialismo com democracia. A menos que se identifique democracia a liberalismo, não faz sentido identificar Lefort à tradição liberal, embora, como todo grande pensador, ele tenha sabido retirar do diálogo crítico com grandes clássicos do liberalismo, como Tocqueville e Weber, um bom proveito ${ }^{5}$. Seria retroceder nas conquistas teóricas de Lefort, muito cioso da gramática republicana de Maquiavel, que pensa ao mesmo tempo o conflito instalado no centro do corpo político e a sua institucionalização, identificá-lo com as culturas de um radicalismo democrático, ingenuamente cultor das virtudes da "sociedade civil" ou de uma noção de autonomia que se organiza contra o Estado. E, por último, seria dissolver a busca de rigor que há em todo o percurso de Lefort, que faz até da abertura de sentido um critério para pensar rigorosamente o político, assimilá-lo a um pensamento sincrético.

A terceira razão para ler o trabalho da obra de Lefort a partir da revolução democrática é que este conceito é o meio através do qual o seu pensamento pensa a história e se historiciza. Se certamente a leitura de Maquiavel formou a classicidade de seu pensamento, já que o pensador florentino o conduziu até à gramática da Roma republicana, é através da identificação das revoluções norte-americanas e francesa que Lefort se instala no Modernidade. E ao conceber a democracia como um princípio que afirma, ao mesmo tempo, a sua identidade e indeterminação, a sua novidade e a sua abertura de sentido, como reinvenção permanente dos direitos, ele se insere de forma dramática na própria cena contemporânea.

É exatamente por este sentido capaz de pensar a filosofia enquanto história e a própria história enquanto filosofia, sempre através da mediação do político, que Lefort está em sua obra em busca do lugar da instituição originária e da possibilidade da refundação. Os temas da

\footnotetext{
${ }^{4}$ Lefort afirma que o liberalismo sempre foi uma força de combate à democracia, tendo procurado interditá-la ao máximo. Ver «Libéralisme et démocratie». In: Le Temps Présent. Paris : Bellin, 2007, p. 747. Ou ainda: "resumindo, trata-se de demolir a expressão democracia burguesa, de explodi-la, enviando cada um dos dois temas a uma história própria e suficientemente complexa para poderem se cruzar sem se confundir". (LEFORT, Claude. “A questão democrática”. In: “ Pensando o político”. São Paulo, Paz e Terra, 1991, p. 34).

${ }^{5}$ Ver como Lefort realiza um diálogo crítico com Weber em “Qu'est-ce que la bureaucratie?”. In: Éléments d'une critique de la bureaucratie. Paris: Éditions Gallimard, 1977. E como dialoga com Tocqueville em "Tocqueville: democracia e arte da escrita". In: Desafios da Escrita política. São Paulo: Discurso Editorial, 1999, na elaboração do seu próprio conceito de revolução democrática.
} 
revolução não são, pois, nem pensados como necessidade ou como um lugar teleologicamente firmado, mas também não são estranhos nem mesmo alheios ao próprio curso deste campo de pensamento.

Em quarto lugar, é interessante pensar que 1968 está para Lefort assim como 1848 está para Marx, isto é, como uma experiência vital de presentificação das potencialidades de uma revolução, mesmo que abruptamente interrompida pelas dinâmicas regressivas da ordem. O pensamento de Lefort será para sempre um pensamento 68, atento aos movimentos sociais disruptivos, às correntes culturais libertárias, ao trabalho das imaginações utópicas inscritas na própria experiência da democracia ${ }^{6}$.

E se muitas vezes o trabalho de pensamento de Lefort apresentou-se na sua individuação e na sua solidão, como um intelectual inorgânico, para utilizar a expressão de Gramsci, isso se deve mais às décadas conservadoras que vão se pondo em camadas na cena histórica do que no pensamento de sua maturidade. Mas um pensamento que se forma na longa maturação e no paciente trabalho de classicização certamente tem capacidade para resistir às conjunturas depressivas. O trabalho da obra de Lefort não cessou porque a democracia não fez ainda o seu trabalho, e pensamentos cada vez mais adversários a ela estão regressivamente desfazendo direitos antes tidos já como cristalizados.

Uma última razão que converge para o mesmo sentido de afirmar a centralidade do conceito de revolução democrática é o modo como ele conceitualiza a experiência do totalitarismo como o grande outro da democracia, mas, ao mesmo tempo, como uma possibilidade nela inscrita, através de um processo de fechamento da indeterminação da identidade e de sentido, em torno ao Uno e a uma direção, de concentração de poder e de ruptura com a experiência da diversidade, da diferença e do pluralismo que caracteriza a vida social em uma democracia.

Assim, para Lefort, se a pulsão do liberalismo conspira contra o princípio da soberania popular e tende a cristalizar na ordem jurídica ou institucional a indeterminação e o processo vivo de reivenção dos direitos que é próprio da democracia, seria interessante desdobrar ou atualizar a crítica de Lefort para as formas dominantes do liberalismo nas últimas décadas, o neoliberalismo, o liberalismo conservador e o chamado libertarianismo, que se apresentam justamente como linguagens políticas liberticidas ${ }^{7}$, isto é, intolerantes ao pluralismo político e societário, privatizantes de toda esfera pública e agressivamente hostis à lógica da formação dos direitos.

\footnotetext{
6 Lefort sempre reafirmou, mesmo na maturidade, a importância das mobilizações de 1968 como uma experiência que tornou possível repensar as potencialidades contidas na democracia no sentido de uma reinvenção permanente dos direitos.

${ }^{7}$ Ver o primeiro capítulo de AMORIM, Ana Paola; GUIMARÃES, Juarez. A corrupção da opinião pública. São Paulo: Boitempo, 2013.
} 
Expostas as cinco razões convergentes que indicam um caminho para se centralizar a leitura de Lefort, faremos este exercício crítico em três etapas - sempre a partir do conceito de revolução democrática - ao longo deste curto ensaio, que se pretende mais delineador de um campo de pesquisa do que propriamente o seu termo.

Em primeiro lugar, reexaminaremos criticamente, a partir de conquistas recentes da interpretação da obra de Marx, a leitura que Lefort fez obra marxiana e do marxismo ${ }^{8}$. Em seguida, e na mesma direção, faremos uma releitura da crítica e do diálogo não desenvolvido na obra de Lefort com o pensamento de Gramsci, que buscou, como ele, a reflexão com Maquiavel para renovar o marxismo. Por fim, em um momento mais praxiológico, interpretaremos o momento dramático vivido pela democracia brasileira através do conceito de revolução democrático, inscrevendo a obra de Lefort na própria cena da conjuntura brasileira.

\section{Lefort, Marx e a revolução democrática}

Já é possível e necessário sistematizar e documentar um juízo crítico sobre a leitura que Lefort faz da obra de Marx, no que diz respeito ao seu sentido, ao seu contexto e ao seu trabalho de interpretação.

Este juízo crítico pode ser assim resumido: Lefort operou no sentido de ler a obra de Marx como uma ruptura com a tradição do republicanismo democrático, buscando através do diálogo com Maquiavel repor a cultura da esquerda em uma linguagem política da liberdade; seria necessário, no entanto, empreender uma crítica mais sistemática e totalizante à leitura que o chamado "marxismo-leninismo" fez da obra de Marx, relendo o sentido da sua obra - a sua gênese, formação e desenvolvimento - como uma atualização crítica do republicanismo democrático no solo da Modernidade. Em síntese, o conceito chave de revolução em Marx, nos termos da auto-emancipação, deveria ser pensado através da revolução democrática.

Havia três fortes razões contextuais de época para explicar o sentido tomado pela obra de Lefort, no sentido de buscar refundar um pensamento político sobre a liberdade fora dos limites da obra de Marx, embora sempre se relacionando com ela. A primeira é de ordem política: a força matricial, paradigmática e irradiadora da URSS e do sistema dos partidos comunistas como referente para a esquerda nas décadas do pós-guerra e da chamada guerra

\footnotetext{
${ }^{8}$ Ver a tese de doutorado "Marx e o republicanismo: Reflexões em torno da liberdade e dos fundamentos do Estado Ético Político”, de Gleyton Trindade, defendida em 2012 no Programa de Pós-Graduação em Ciência Política da UFMG, na qual se desenvolvem extensamente os argumentos cujo último desenvolvimento se expressam neste ensaio.
} 
fria. Interpretar e formar um juízo público sobre a URSS era, pois, um fundamento incontornável de uma identidade e de uma práxis de esquerda.

Este pensamento juvenil de Lefort, que nasce já em uma relação com uma subcultura herética e posta à margem do estalinismo, a tradição trotskista, se porá a reflexão sobre os limites desta crítica, e se moverá, então, de dentro para fora da cultura do bolchevismo. No final dos anos quarenta, com a fundação de Socialismo ou barbárie, Lefort já não é um "russo", nos termos postos por Perry Anderson em torno à imprecisa definição de "marxismo ocidental". Mas por que não continuaria a ser um marxista mesmo nos quadros de um "marxismo crítico"?

Parece-nos que este segundo momento, das margens da cidadela do marxismo oficial para fora do próprio campo do marxismo, tem uma forte explicação na impregnação e sedimentação histórica da interpretação da obra de Marx pela cultura do chamado "marxismoleninismo". $\mathrm{Na}$ época do pós-guerra, na qual a cultura "marxista-leninista" adquiriu a sua expressão máxima, já haviam se superposto três gerações de interpretação de Marx a partir da experiência russa: a primeira leninista, do período da chamada bolchevização dos partidos atraídos e integrados à III Internacional; a década de trinta, que é um período de sistematização e formação do chamado Diamat ou "materialismo histórico" e "materialismo dialético", e, por fim, o período do pós-guerra marcado exatamente pela polarização e estrita partidarização da leitura da obra de Marx.

Um paradigma de interpretação de um autor torna-se hegemônico em uma dada época por estabelecer um horizonte e uma problemática, não necessariamente por oferecer um mapa conceitual único ou homogêneo de respostas. Neste sentido, o paradigma "marxista-leninista" de interpretação do marxismo passou certamente por muitas fases de adaptação ou flexibilização ${ }^{10}$. Mas o limite intransponível posto por esta problemática seria sempre o de que a identidade da obra de Marx deveria ser entendida historicamente como uma ruptura com as tradições das chamadas culturas das "revoluções burguesas", fossem elas chamadas de liberais, republicanas burguesas ou pequeno-burguesas. Por esta via - a da ruptura científica do pensamento de Marx com as filosofias da chamada revolução burguesa - fazia-se a fusão entre a obra de Marx e uma filosofia da história, entre um pensamento orgânico à burguesia e um pensamento orgânico ao proletariado, entre a vigência do capitalismo e a revolução proletária.

A força deste paradigma de interpretação da obra de Marx foi tão impressionante que mesmo os vários pensamentos chamados de "marxismos críticos", que vicejaram nas décadas

\footnotetext{
${ }^{9}$ Ver o quarto capítulo do livro GUIMARÃES, Juarez. Democracia e marxismo: Crítica à razão liberal. São Paulo: Editora Xamã, 1998, no qual se sistematizam as origens e o desenvolvimento da tradição do chamado Diamat.

${ }^{10} \mathrm{O}$ livro de referência para o processo de adaptação do dogma da filosofia da URSS, organizada em torno ao chamado materialismo histórico e dialético, é o de SCANLAN, James P. Marxism in the USSR: A Critical Survey of Current Soviet Thought. Ithaca and London: Cornell UP, 1985.
} 
de lenta e crescente crise do estalinismo como referente cultural, não ousaram desafiar esta interpretação da ruptura de Marx com as filosofias políticas do republicanismo democrático. Nem Lukács ou Adorno, nem Sartre e muito menos Althusser, nem as culturas do eurocomunismo ou a grande escola historiográfica formada em torno a Hobsbawm, nem o "marxismo analítico" nem Habermas, superaram a tese estalinista da ruptura da obra de Marx com o republicanismo democrático. O "político" e sua linguagem permaneceram estranhos a estes pensamentos críticos, por mais enriquecimento reflexivo e de conhecimento que certamente trouxeram ${ }^{11}$. Apenas nos anos mais recentes, nos tempos próprios da cultura que nem sempre são os da história política, esta dimensão central do paradigma de interpretação "marxista-leninista" da obra de Marx começou a ser, de fato, superada.

Chegamos a uma terceira razão de época limitadora da leitura que Lefort fez da obra de Marx. Nos anos sessenta e setenta do século passado, estava ainda se formando o grande empreendimento de pesquisa histórica e erudita, centrada no mundo anglo-saxão, de reinterpretação das revoluções do século XVII inglês, do século XVIII na França e nos Estados Unidos a partir das tradições originadas no humanismo cívico italiano. São das duas últimas décadas a rica recomposição da cultura republicana da Alemanha no século XIX, em particular uma releitura da obra dos jovens hegelianos, contexto no qual Marx se formou ${ }^{12}$. E, mais decisivo, Lefort não poderia contar em sua interpretação da obra de Marx com a chamada edição Mega, que além da edição integral das obras não publicadas de Marx, com seus rascunhos e incompletudes, permite o acesso aos famosos cadernos de estudos de Marx, possibilitando acompanhar passo a passo as suas leituras, em particular a sua formação em filosofia clássica, greco-romana, renascentista e moderna, o que incluía Maquiavel e Espinosa, os franceses do século XVIII, Tocqueville e o utilitarismo inglês, toda a imensa cultura

\footnotetext{
${ }^{11}$ No livro Democracia e marxismo: Crítica à razão liberal, examinam-se sucessivamente estas diversas tentativas de repensar a filosofia do marxismo em sua incapacidade de superarem ou oferecerem uma alternativa às concepções deterministas da história, seja na forma de uma filosofia da história, de uma ciência da história ou de uma teoria da história. Como se argumenta neste livro, concepções deterministas da história constituem um limite insuperável para se constituir uma linguagem política coerente da liberdade e da democracia.

12 Ver, entre outros, LEOPOLD, David. The Young Karl Marx. German philosophy, modern politics and buman flourishing. Cambridge: Cambridge University Press, 2007; HEIDEKING, Jürgen; HENRETTA, James A. (eds.). Republicanism and liberalism in America and the German state 1750-1850. Washington: Publications of the German Historical Institute, 2004; MOGGACH, Douglas. The new Hegelians. Politics and philosophy in the Hegelian school. Cambridge: Cambridge University Press, 2006; MOGGACH, Douglas. The philosophy and politics of Bruno Bauer. Cambridge: Cambridge University Press, 2003; MOGGACH, Douglas. The social question and the democratic revolution: Marx and the legacy of 1848. Ottawa: Ottawa University Press, 2000; FISCHER, Norman Arthur. Marxist Ethics within Western Political Theory. A Dialogue with Republicanism, Communitarianism, and Liberalism. New York: Palgrave Macmillan, 2015; BRECKMAN, Warren. Marx, the young Hegelians ant the origins of radical social theory. Cambridge: Cambridge University Press, 1999; LACASCADE, Jean-Louis. «Les métamorphoses du jeune Marx ». Paris: PUF, 2002; BRUDNEY, Daniel. Marx's attempt to leave philosophy. Cambridge, Massachusetts: Harvard University Press, 1998.
} 
filosófica do século XIX na Alemanha, além dos pensamentos políticos franceses da primeira metade do século XIX ${ }^{13}$.

Além disso, a leitura da obra de Marx como uma ruptura com a tradição do republicanismo democrático parecia verossímil e legítima quando se constatam que tensões deterministas da história comparecem desde o início em sua obra ${ }^{14}$, que a auto-interpretação de Marx de sua obra inseria-se no contexto da crise da cultura do republicanismo democrático pós-revolução francesa e em meio à ascensão de uma posição dominante e hegemônica do liberalismo, e que, além disso, a primeira sedimentação filosófica na cultura do marxismo deve muito aos trabalhos de autoria e de edição de Engels que formaram uma primeira versão do "materialismo histórico" e indicavam esta compreensão ${ }^{15}$.

Hoje, em uma época histórica que se desenvolve a partir da desagregação política da URSS, na qual a cultura do chamado "marxismo-leninismo" entrou em uma fase de dissolução e na qual já há na história da filosofia política do Ocidente uma importante recuperação da cultura do republicanismo democrático, é possível repor e documentar nas obras completas agora publicadas de Marx a sua relação seminal e de pertencimento a esta tradição.

Estas novas interpretações e documentações permitem, hoje, enfim, após décadas de crítica à grande narrativa sobre a formação, a identidade e o sentido do marxismo dogmatizada na III Internacional estalinizada, construir uma narrativa alternativa e coerente da formação, identidade e sentido da obra de Marx. Sem uma narrativa globalmente coerente e alternativa, não se supera o paradigma estalinista: o atual estado de fragmentação das culturas do marxismo é bem uma demonstração disso ${ }^{16}$.

Esta narrativa coerente e alternativa sobre a formação, identidade e sentido da obra de Marx pode ser resumida em quatro dimensões mutuamente configuradas.

13 A Edição MEGA da obra completa de Marx é um empreendimento internacional e interdisciplinar que compreende quatro partes: a primeira edita toda a obra, os artigos e esboços, excluindo $O$ Capital; a segunda, $O$ Capital e todo o seu trabalho preparatório desde 1857; a terceira abarca todo o epistolário e a quarta os estratos, as anotações e escritos marginais. São previstos, ao todo, 114 volumes.

14 Estas tensões deterministas resultam, no fundamental, da cultura da época na qual predominava amplamente visões deterministas da história, como na filosofia alemã, na economia política inglesa, no materialismo francês da época do iluminismo. É interessante que mesmo o liberal mais avançado do século XIX, John Stuart Mill, advoga teses deterministas da história, que se evidenciariam na legalidade de longo prazo. No caso de Marx, estas tensões deterministas jamais alcançam uma coerência ou fixação em função do conceito praxiológico de autodeterminação, que comparece no centro de sua teoria.

${ }^{15}$ Ver o capítulo segundo do livro Democracia e marxismo: Crítica à razão liberal. Engels, de fato, seguia na mesma direção de correntes de pensamento muito influentes na segunda metade do século XIX na Alemanha que pensavam o desenvolvimento da ciência como a superação de questões secularmente postas no âmbito da tradição filosófica.

${ }^{16} \mathrm{Um}$ mapeamento exaustivo e rico das diversas correntes e temáticas do marxismo contemporâneo está em BIDET, Jacques; KOUVELAKIS, Stathis (eds.). Critical companion to contemporary Marxism. Netherlands: Brill Academic Publishers, 2005. 
Em primeiro lugar, Marx nunca foi propriamente um liberal que se orientou para uma ruptura em direção ao comunismo. A sua primeira crítica ao Estado prussiano era basicamente expressa na linguagem do republicanismo democrático, mediado pela cultura do republicanismo alemão do século XIX, e, a partir principalmente da Crítica à Filosofia do Direito de Hegel, ele já está orientando a sua crítica ao Estado moderno liberal ${ }^{17}$. Esta crítica deve ser entendida, de fato, como uma atualização do republicanismo democrático às dimensões opressivas do Estado liberal moderno e do sistema capitalista moderno, isto é, da ordem política liberal, que Marx avalia como melhor exemplificada pelo sistema político norteamericano, e da sociedade civil liberal, que Marx principiou estudar através de seu conhecimento da economia política inglesa. Neste sentido, o socialismo democrático de Marx é um republicanismo atualizado para o período do capitalismo e da ordem liberal e $O$ Capital deve ser entendido como parte fundamental da crítica ao Estado liberal moderno.

Em segundo lugar, não é verdade que Marx rompeu com a filosofia política clássica e se orientou para construir uma ciência da história, que seria o materialismo histórico, uma visão linear e teleológica ou finalista da sequência dos modos de produção que culminariam com o advento inevitável do comunismo. O que há são tensões deterministas que nunca chegam a estabilizar uma filosofia uma ciência ou teoria da história, travados que são por um conceito praxiológico central de auto-emancipação ${ }^{18}$. Hoje, com seus cadernos de estudos, com a edição verdadeira e não instrumentalizada da Ideologia Alemã, sabemos como Marx tinha uma formação sólida em cultura política. Esta cultura filosófica está presente em toda obra e é impossível ler O Capital sem esta formação filosófica. A obra de Marx não deve ser entendida como uma ciência determinista da história mas como centralizada em uma política da emancipação, com um princípio ativo e praxiológico de superação do capitalismo através da luta política consciente a partir de suas contradições imanentes ${ }^{19}$.

Em terceiro lugar, não é verdade que Marx moveu-se do idealismo ao materialismo, abraçando uma visão materialista ontológica do mundo social que tornaria sua teoria incompatível com o próprio princípio da liberdade humana. Marx nunca foi propriamente um

\footnotetext{
17 São documentos muito expressivos desta linguagem republicana os primeiros escritos públicos de Marx na Gazeta Renana, em particular os seus escritos sobre a liberdade de expressão e o seu sentido para a democracia. O fundamento de Marx nestes escritos é a crítica ao Estado prussiano a partir da tradição do republicanismo democrático e da razão pública.

18 Este sistema de travas ao determinismo no coração de sua teoria pode ser bem identificado na sua crítica à naturalização do capitalismo presente na economia política inglesa, reivindicando a sua historicização e fazendo a crítica às suas categorias reificadas através de um perspectiva humanista, a crítica ao que há de especulativo em Hegel, retomando ao terreno do princípio da soberania popular e de uma história construída pelos homens e, enfim, criticando a unilateralidade dos pensamentos materialistas ou idealistas, como se afirma nas famosas Teses sobre Feuerbach.

${ }^{19}$ Esta é a grande contribuição da tese doutoral de LÖWY, Michael. «La théorie de la révolution chez le jeune Marx ». Paris: François Maspero, 1970.
} 
idealista e não se tornou decididamente um iluminista e materialista francês: sua vida, obra e ação estão todas orientadas para a política em seus condicionamentos de classe ${ }^{20}$. São inúmeras as passagens em que ele critica o materialismo e o idealismo como filosofias inconsistentes, formulando a alternativa de uma filosofia da práxis. O termo "materialista" aparece para delimitar o campo fundamental dos interesses econômicos de classe, para se opor realisticamente às especulações idealistas, para vincular pensamento revolucionário às condições imanentes da luta de classes.

Por fim, Marx nunca defendeu um caminho autocrático de revolução ou mesmo um conceito elitista ou vanguardista de revolução. Desde o princípio, como herança do republicanismo democrático, é o princípio da autodeterminação, do demos total ao proletariado, que vai ao centro de sua teoria da revolução. A expressão "ditadura do proletariado", que surge em diálogo crítico com o conceito blanquista de "ditadura revolucionária", nunca foi desenvolvida como alternativa ou em detrimento do conceito de uma revolução democrática, isto é, de uma revolução que usa a força como princípio ativo legitimado pelo direito democrático formado pelas maiorias que fazem a revolução.

Um bom exemplo dos limites e dos erros de interpretação da obra de Marx por Lefort está no ensaio "Direitos do homem e política", de maio de 1979, que abre o belo e fundamental livro L'invention démocratique: les limites de la domination totalitaire ${ }^{21}$. Nele, Lefort toma como base da crítica o ensaio de Marx, A questão judaica (1844), no qual polemiza com Bruno Bauer.

Há, em síntese, três grandes problemas na leitura que Lefort faz aí de A questão judaica, de Marx, em polêmica com Bruno Bauer. Uma dimensão de contexto argumentativo, um de sentido da interpretação e outro de conteúdo mesmo da interpretação.

A dimensão de contexto argumentativo diz respeito, no fundamental, ao largo desconhecimento da obra de Bruno Bauer, que só foi recentemente editada e interpretada pelo magnífico trabalho de investigação levada a cabo por Douglas Moggach ${ }^{22}$. Esta reconstituição do pensamento de Bauer, em particular da fase política de seus escritos republicanos, entre 1843 e 1845, é fundamental, pois Marx erra o entendimento das posições de Bauer sobre a chamada emancipação dos judeus e faz uma polêmica cruzada, utilizando-se das posições atribuídas a Bauer para desenvolver seus argumentos em outra direção, de crítica ao chamado Estado moderno (ou estado liberal). Isto é, Bauer (segundo Marx) teria defendido que um

\footnotetext{
${ }^{20}$ Este argumento é exposto de forma brilhante no livro CASCADE, Jean-Louis. Les métamorphoses du jeune Marx. Paris: PUF, 2002. No seu penoso e árido trabalho de demarcação com as diferentes seitas e movimentos vinculados ao movimento operário em formação, é a centralidade da política para a emancipação em Marx que vem ao primeiro plano.

${ }^{21}$ LEFORT, Claude. L'invention démocratique : les limites de la domination totalitaire. Paris: Arthème Fayard, 1981.

${ }^{22}$ MOGGACH, Douglas. The philosophy and politics of Bruno Bauer. Cambridge: Cambridge University Press, 2003
} 
Estado liberal moderno seria incompatível com a continuidade da crença religiosa. Isto seria empiricamente negado, diz Marx, pelo fato do vigor da religião entre os norte-americano, que viviam na forma mais acabada de desenvolvimento do Estado moderno. Mas o argumento de Bauer é que a formação de uma república só seria possível com a superação completa da crença religiosa entre os cidadãos, fazendo da crítica às dimensões teológicas da legitimidade do Estado prussiano o centro de sua crítica. Para Bauer, o judaísmo seria, por excelência, uma religião marcada pelo particularismo da identidade, marcando, neste sentido, um recuo em relação ao universalismo cristão ${ }^{23}$.

Em segundo lugar, há um problema na direção da crítica de Lefort. Isto é, faz falta à sua leitura uma apreensão sistemática dos escritos de Marx nestes anos decisivos, o que acaba por comprometer o sentido da crítica que Marx faz à realidade dos direitos afirmados pela revolução francesa. Seguindo aqui a leitura erudita e convincente que David Leopold em seu The Young Karl Marx. German philosophy, modern politics, and human flourishing, Marx está, em A questão judaica, empenhado em ligar a sua crítica ao materialismo da sociedade civil mercantil ao idealismo da vida do cidadão no Estado moderno ou liberal, isto é, ao fato dos cidadãos aparecem atomizados e competitivos na vida mercantil e atomizados e sem real poder de soberania sobre o Estado no exercício de seus direitos políticos ${ }^{24}$. Esta compreensão de Marx das limitações emancipatórias do Estado moderno ou liberal, apesar de reconhecer neles um avanço em relação à realidade anterior, vinha sendo construída nos textos fundamentais desta época como em Crítica à Filosofia do Direito de Hegel, nos Manuscritos Econômico-Filosóficos, em suas polêmicas com Feuerbach, Bauer e Stirner. Sem esta narrativa de sentido, perde-se o que Marx quer dizer quando fala dos limites da "emancipação política" em A questão judaica, isto é, de uma pretensa emancipação incapaz de retirar os homens de sua atomização mercantil e de sua impotência em relação a um real exercício da soberania.

Em consequência destes dois problemas, Lefort não acerta o conteúdo da crítica de Marx aos chamados direitos humanos nestes famosos escritos. O que Marx está formulando é que, nos quadros do liberalismo da época, estes direitos proclamados antes como genericamente universais serviam apenas para mascarar uma dominação brutal na sociedade civil e na sociedade política sobre os chamados "cidadãos"25. Que a França monárquica liberal

${ }^{23}$ BAUER, Bruno. The Jewish problem. Traduzido por Helen Lederer. Cincinnati, Union College: Jewish Institute of Religion, 1938; e The capacity of present-day jews and Christians to become free. Traduzido por Michael P. Malloy. The philosophical forum, vol. 8, 1978.

24 LEOPOLD, David. The young Karl Marx-German philosophy, modern politics and buman flourishing. Cambridge: Cambridge University Press, 2007.

${ }^{25}$ Ver, por exemplo, a afirmação de Marx em Kritick Einsleitung, “ the categorical imperative to overthrow all conditions in which man is a debased, enslaved, neglected and contemptible being [ein erniedrigtes, ein geknechtetes, ein verlassenes, ein verachtliches Wesen]", citado por David Leopold, op. cit., p.155. Marx, tendo 
censitária de 1832 seja vista como a verdade da França revolucionária de 178926, que Rousseau seja lido como um mero contratualista jusnaturalista ${ }^{27}$, que os direitos humanos sejam lidos como burgueses não pode eclipsar o fato de que o que Marx está criticando - contra leitura do paradigma "marxista-leninista- é a insuficiência da matriz ideológica liberal de reinterpretação destes direitos darem lugar a uma verdadeira liberdade, a uma emancipação plena. A obra de Marx do período está plena de juízos humanistas veementes, críticos e afirmativos, em favor dos direitos plenos do homem e do cidadão ${ }^{28}$.

Enfim, este texto fundamental para definir a relação da obra de Lefort com Marx está cheio de juízos de época que precisam ser reexaminados e relidos. Que um grande autor, mesmo no momento do erro, ensine-nos muito, não deixa de ser impressionante: pois Lefort está, aqui, colocando no centro a relação de Marx com as revoluções republicanas que formaram a Modernidade. Que a sua resposta não tenha sido, a partir do que hoje se conhece, consistente, é menos importante do que o sentido transcendente da problemática que repõe para a própria identidade e futuro da esquerda.

\section{Lefort, Gramsci e Marx}

O capítulo VII de Le Travail de l'cuvre Machiavel, "La première figure de la philosophie de la práxis - Antonio Gramsci”, é certamente uma das peças mais duras e fechadas à abertura

recém lido Maquiavel e Rousseau, retoma os temas da contradição entre o cristianismo e a república, em um sentido inverso à interpretação de Lefort.

${ }^{26}$ Ver o excelente ensaio de George Comninel, "Revolution in history: the Communist Manifesto in context". In: The social question and the democratic revolution: Marx and the legacy of 1848. Ed. by Douglas Moggach e Paul Leduc Browne. Otawa: University of Otawa Press, 2000. George Comninel é autor de Rethinking the French Revolution: Marxism and the revisionist challenge. London: Verso, 1987.

${ }^{27}$ É esta a leitura que faz Hegel de Rousseau e que o jovem Marx, tendo recém lido O Contrato Social, segue. Isto é decisivo: o grande autor do republicanismo democrático moderno é lido como alguém que pensa a liberdade do indivíduo isolado de seu contexto social e histórico. Marx ainda não tem uma leitura sistemática da obra de Rousseau e muito menos a filiação republicana e maquiaveliana de seu pensamento. É interessante, neste sentido, que a citação de Rousseau, feita por Marx em A questão judaica para demonstrar a abstração do homem político, interrompe a frase exatamente no ponto em que ela desmente a sua interpretação. Isto é, o trecho "d'altérer la constitution de l'homme pour la renforcer» (O Contrato Social, Livro II, Capítulo VII, "Du Legislateur”). O que Rousseau trata aí é do momento da instituição da república democrática, no qual é preciso recriar, em uma dimensão intersubjetiva, a liberdade do homem como cidadão inserido em um povo soberano. Ou seja, é exatamente o momento convencional da criação da liberdade, que não pode ser entendida como liberdade natural, à qual não é mais possível retornar.

${ }^{28}$ A leitura de $A$ questão judaica de Marx como antagonista à própria idéia de direitos prevaleceu na cultura liberal anglo-saxã como em PEFFER, Rodney G. Marxism and Social Justice. Princeton: Princeton University Press, 1990. KAIN, Philip J. Mans and Ethics. Oxford: Oxford University Press, 1988. EDMUNSON, William A. An Introduction to rights. Cambridge: Cambridge University Press, 2004; e BUCHANAN, Allen E. Marx and Justice: the radical critique of liberalism. Totowa, New Jersey: Rowman and Littlefield, 1982, mostrando o caráter de época desta interpretação, como documenta David Leopold. 
de sentidos deste grande leitor que é Lefort. O objetivo é certamente o de fazer frente à cultura do euro-comunismo, cuja consciência média procurava fazer da obra de Gramsci editada por Togliatti uma peça de acomodação ou mediação, garantida a autonomia do caminho italiano para o socialismo, com a cultura do estalinismo. O Gramsci de Lefort é o Gramsci editado, lido e interpretado pelo euro-comunismo.

Aqui, mais até do que no caso da leitura de $A$ questão judaica, de Marx, os limites e erros de interpretação de Lefort derivam de uma insuficiente contextualização, de uma atribuição de sentido e do próprio conteúdo do diálogo entre Gramsci e Maquiavel.

Em primeiro lugar, o material de leitura de Lefort é a edição temática de Togliatti dos Cadernos do Cárcere, de 1949, "Note sul Machiavelli, sulla politica e sullo Stato moderno". Não estava ainda à disposição de Lefort a edição crítica integral dos Cadernos do Cárcere, de Valentino Gerratama, de 1972, que permitiu toda uma nova geração de estudos interpretativos sobre Gramsci, livres já de uma apropriação instrumental, e que se centralizaram cada vez mais, de forma consistente, na proposta gramsciana de refundação filosófica do marxismo a partir da sua inscrição como uma filosofia da práxis ${ }^{29}$. Ainda não eram conhecidas publicamente a crítica de Gramsci ao estatismo estalinista nem a sua aberta tensão com as diretivas da III Internacional estalinizada ${ }^{30}$.

Não faz parte da leitura de Lefort também a inteligência discursiva de Gramsci que está, em suas reflexões sobre Maquiavel, opondo-se à interpretação liberal que Benedetto Croce faz de Maquiavel. Acompanhamos aqui a interpretação de Benedetto Fontana em Hegemony and power. On the relation between Gramsci and Machiavelli ${ }^{31}$, que documenta como o diálogo com Maquiavel está no centro da sua formulação do conceito de hegemonia. Ao contrário de Crocce, que interpreta a obra de Maquiavel como aquela que separa kratos de ethos, a moralidade da política de poder entendida como o jogo realista de astúcia e força, Gramsci, ao eleger Maquiavel como o primeiro grande filósofo da práxis, quer trilhar o caminho contrário, vincando a construção da revolução e a luta por um novo estado ao desenvolvimento de uma "filosofia democrática", que superasse a distinção elite/massa.

Ao centralizar a sua leitura de Gramsci no par partido/moderno príncipe, na linha da edição de Togliatti, Lefort, então, interpreta Gramsci como propositor apenas de uma mediação entre as massas e o partido/Estado, isto é, literalmente como um pensador orgânico à cultura do estalinismo. $\mathrm{O}$ que significa exatamente literalmente inverter todo o trabalho

${ }^{29}$ O tema dos Cadernos do Cárcere como uma proposta de refundação do marxismo como filosofia da práxis é desenvolvido, entre outros, por Juarez Guimarães, Giovanni Semeraro, Giorgio Baratta, Álvaro Bianchi, Peter Yves, Benedetto Fontana.

${ }^{30}$ Ver SACCARELLI, Emanuele. Gramsci and Trotsky in the shadow of stalinism. The political theory and practice of opposition. London: Routledge, 2009.

${ }^{31}$ FONTANA, Benedetto. Hegemony and power. On the relation between Gramsci and Macbiavelli. Minnesota: Minnesota University Press, 1993. 
seminal, reflexivo e aberto de Gramsci nos Cadernos do Cárcere, historicamente o principal documento no século XX de um retorno do marxismo à cultura do republicanismo democrático ${ }^{32}$.

Como dois autores que têm muito de afinidade, seria possível ler Lefort leitor e atualizador de Maquiavel através do Gramsci leitor e atualizador de Maquiavel. O que Gramsci traria ao corpo da obra de Lefort, através do conceito de hegemonia que centraliza toda a sua ordem conceitual, seria a ênfase naquilo que dá unidade ao corpo político e que institucionaliza o conflito inarredável de sua constituição originária, a república democrática como uma conquista histórica da Modernidade mas que a partir do século XIX passou a ser hegemonizada pela tradição liberal, a revolução democrática mais claramente como a superação histórica da ordem capitalista organizada pela democracia liberal.

\section{Lefort, a revolução democrática e a crise da democracia brasileira}

Este trabalho de leitura crítica de Lefort é necessário para pensar, com toda potência, o momento lefortiano vivido pela experiência da esquerda brasileira, isto é, a relação entre seus impasses com a cultura do republicanismo democrático. Se, diante de um capitalismo precariamente contido em suas dinâmicas de barbárie, sem Marx, a esquerda perde o seu sinal de identidade; se em uma democracia tão precariamente republicanizada, sem Gramsci, a esquerda não conseguir trilhar o caminho da hegemonia; sem Lefort, a esquerda não consegue, diante de um neoliberalismo tão agressivamente privatista, firmar o princípio do que é público por ser democrático. O conceito de revolução democrática, através do paciente trabalho de releitura crítica destes três autores, seria, ao mesmo tempo, uma plataforma crítica e um caminho de esperança e renovação da esquerda brasileira.

O principal partido da esquerda brasileira, o PT, foi historicamente fruto da convergência de muitas correntes políticas e de um longo processo de mediação cultural, internacional e nacional. O seu ato de fundação foi exatamente o da relação entre socialismo e democracia, criando um leito comum entre um sindicalismo classista que buscava romper com o horizonte corporativista, correntes da igreja da Libertação que repunham o espírito da liberdade no centro de sua práxis pastoral, movimentos sociais em busca de seus direitos na democracia, organizações de esquerda que avançavam no seu trabalho de desestalinização e

\footnotetext{
32 Subindo o tom em seu juízo arbitrário, Lefort chega a postular que Gramsci, na sua empreitada de mediador entre Maquiavel e Marx, fornece a prova de sua "impostura", atenuando a formulação em seguida, precisando que usa o termo não no sentido psicológico ou moral. LEFORT, Claude, op. cit., p. 253.
} 
intelectuais críticos que já formulavam no campo de um socialismo e republicanismo democrático ${ }^{33}$.

A partir das eleições presidenciais de 1994, e cada vez mais, esse partido, mantendo e até expandindo a sua raiz social e densidade eleitoral, formou-se como um poderoso ator capaz de disputar poder nas instituições semi-republicanas da democracia brasileira resultante da transição conservadora e da Constituição de 1988. A chegada ao governo central do país, se permitiu um criativo trabalho de alargamento e republicanização das instituições, sempre no limite institucional de um Congresso majoritariamente conservador e de uma economia já regulada a partir de fundamentos típicos da regulação neoliberal, por outro lado foi, ao longo do tempo, exacerbando a adaptação da esquerda brasileira ao que havia de anti-republicano nas práticas e modos de funcionamento das instituições do Estado brasileiro.

Principalmente no campo das políticas de trabalho e de direitos públicos, de assistência, educação e saúde, as conquistas foram inéditas e em proporções magníficas. Mas, justamente no campo democrático, estas conquistas foram limitadas, em particular no que diz respeito à democratização da gestão macro-econômica, das políticas de comunicação pública, das políticas de segurança pública, nos direitos dos gays e das pautas libertárias, na própria financeirização das dinâmicas eleitorais.

É esta experiência generosa, porém incapaz de mudar os fundamentos antirepublicanos de reprodução da democracia brasileira, que foi, de forma cada vez mais virulenta, desestabilizada pelas novas linguagens neoliberais e neo-conservadoras nos últimos anos. Uma experiência de centro-esquerda e uma linguagem de centro-esquerda revelaram-se incapazes de fazer frente a uma nova direita, renovada na radicalidade de seu programa de exterminar o que é público, disposta a incendiar os mínimos padrões de civilidade e tolerância, de utilizar sem freios a violência midiática e judicial partidarizada.

Não se pode vencer as chamadas paixões tristes - o ódio, a intolerância, o racismo, o machismo, o desejo de anatemizar, excluir, violentar e até exterminar - com as paixões conformadas e desbotadas por uma vontade política incapaz de ir à raiz de seu fundamento democrático, como apontava Lefort. Mais do que nunca, a esquerda brasileira precisa da inteligência, da vontade, das paixões e de todas as cores da revolução democrática.

\footnotetext{
${ }^{33}$ Certamente, na origem e na história desta cultura, o pensamento mais alto no sentido socialista, republicano e democrático tem sido aquele formulado, de modo coerente e absolutamente íntegro, por Marilena Chauí.
} 


\section{Referências bibliográficas}

AMORIM, Ana Paola; GUIMARÃES, Juarez. A corrupção da opinião pública. São Paulo: Boitempo, 2013.

BAUER, Bruno. The capacity of present-day jews and Christians to become free. Traduzido por Michael P. Malloy. The philosophical forum, vol. 8, 1978.

. The Jewish problem. Traduzido por Helen Lederer. Cincinnati, Union College: Jewish Institute of Religion, 1938

BIDET, Jacques; KOUVELAKIS, Stathis (eds.). Critical companion to contemporary Marxism. Netherlands: Brill Academic Publishers, 2005.

BRECKMAN, Warren. Marx, the young Hegelians ant the origins of radical social theory. Cambridge: Cambridge University Press, 1999.

BRUDNEY, Daniel. Marx's attempt to leave philosophy. Cambridge, Massachusetts: Harvard University Press, 1998.

BUCHANAN, Allen E. Marx and Justice: the radical critique of liberalism. Totowa, New Jersey: Rowman and Littlefield, 1982.

CASCADE, Jean-Louis. Les métamorphoses du jeune Marx. Paris: PUF, 2002.

COMNINEL, George. "Revolution in history: the Communist Manifesto in context". In: The social question and the democratic revolution: Marx and the legacy of 1848. Ed. by Douglas Moggach e Paul Leduc Browne. Otawa: University of Otawa Press, 2000.

Rethinking the French Revolution: Marxism and the revisionist challenge. London: Verso, 1987.

EDMUNSON, William A. An Introduction to rights. Cambridge: Cambridge University Press, 2004.

FISCHER, Norman Arthur. Marxist Ethics within Western Political Theory. A Dialogue with Republicanism, Communitarianism, and Liberalism. New York: Palgrave Macmillan, 2015.

FONTANA, Benedetto. Hegemony and power. On the relation between Gramsci and Machiavelli. Minnesota: Minnesota University Press, 1993. 
GUIMARÃES, Juarez. Democracia e marxismo: Crítica à razão liberal. São Paulo: Editora Xamã, 1998.

HEIDEKING, Jürgen; HENRETTA, James A. (eds.). Republicanism and liberalism in America and the German state 1750-1850. Washington: Publications of the German Historical Institute, 2004.

KAIN, Philip J. Mans and Ethics. Oxford: Oxford University Press, 1988.

LACASCADE, Jean-Louis. «Les métamorphoses du jeune Marx ». Paris: PUF, 2002;

LEFORT, Claude. “A questão democrática”. In: “ Pensando o político”. São Paulo, Paz e Terra, 1991.

. “Qu'est-ce que la bureaucratie?”. In: Éléments d'une critique de la bureaucratie. Paris: Éditions Gallimard, 1977.

. “Tocqueville: democracia e arte da escrita". In: Desafios da Escrita política. São Paulo: Discurso Editorial, 1999.

- «a contradiction de Trotsky». In : Éléments d'une critique de la bureaucratie. Paris : Éditions Gallimard, 1974.

. «Libéralisme et démocratie ». In : Le Temps Présent. Paris : Bellin, 2007.

1981.

. L'invention démocratique : les limites de la domination totalitaire. Paris: Arthème Fayard,

LEOPOLD, David. The Young Karl Marx. German philosophy, modern politics and human flourishing. Cambridge: Cambridge University Press, 2007.

LÖWY, Michael. «La théorie de la révolution chez le jeune Marx ». Paris: François Maspero, 1970.

MOGGACH, Douglas. The new Hegelians. Politics and philosophy in the Hegelian school. Cambridge: Cambridge University Press, 2006.

. The philosophy and politics of Bruno Bauer. Cambridge: Cambridge University Press, 2003.

. The social question and the democratic revolution: Marx and the legacy of 1848. Ottawa: Ottawa University Press, 2000;

PEFFER, Rodney G. Marxism and Social Justice. Princeton: Princeton University Press, 1990.

SACCARELLI, Emanuele. Gramsici and Trotsky in the shadow of stalinism. The political theory and practice of opposition. London: Routledge, 2009. 
SCANLAN, James P. Marxism in the USSR: A Critical Survey of Current Soviet Thought. Ithaca and London: Cornell UP, 1985.

TRINDADE, Gleyton Carlos da Silva. "Marx e o republicanismo: Reflexões em torno da liberdade e dos fundamentos do Estado Ético Político". Tese de doutorado (2012). Programa de Pós-Graduação em Ciência Política da UFMG. 